\title{
Aortic Saddle Embolism Caused by Left Ventricular Thrombus in a Patient with Cardiac Sarcoidosis
}

\author{
Kimiaki Nagase ${ }^{1}$, Akira Tamura ${ }^{2}$, Yoichi Tatsukawa ${ }^{1}$ and Junichi Kadota ${ }^{2}$
}

Key words: cardiac sarcoidosis, saddle embolism, left ventricular thrombus

\section{(DOI: 10.2169/internalmedicine.46.6195)}

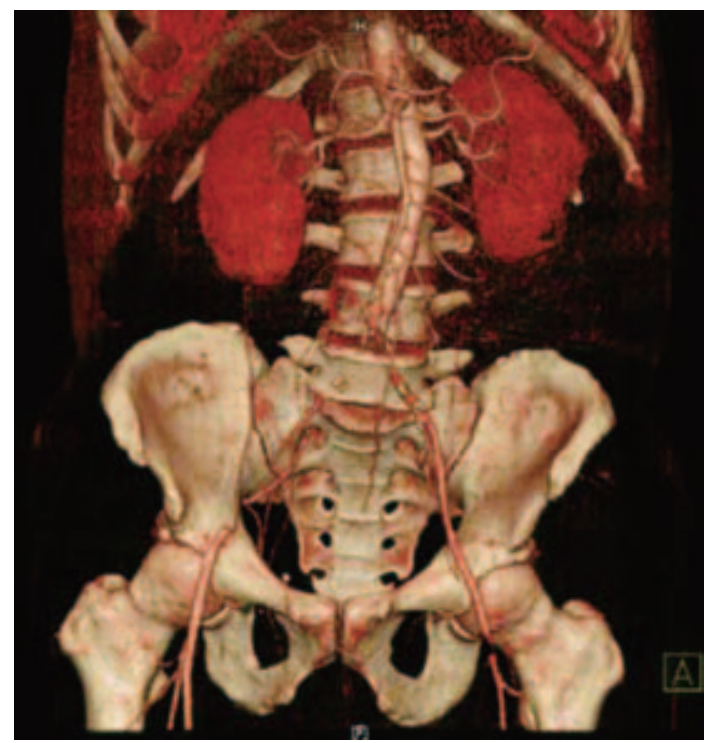

Figure 1. Multislice computed tomography showed an obstruction of the distal abdominal aorta.

A 54-year-old man was admitted to our hospital because of palpitation. On day 3 , he suddenly experienced lower abdominal pain radiating to the bilateral lower extremities. The bilateral femoral arteries were not palpable. Multislice computed tomography showed an obstruction of the distal abdominal aorta (Fig. 1) and a thrombus in the posterobasal region of the left ventricle (LV). An urgent transfemoral thrombectomy using a Forgarty balloon catheter was thus performed, and a large amount of thrombus was removed.

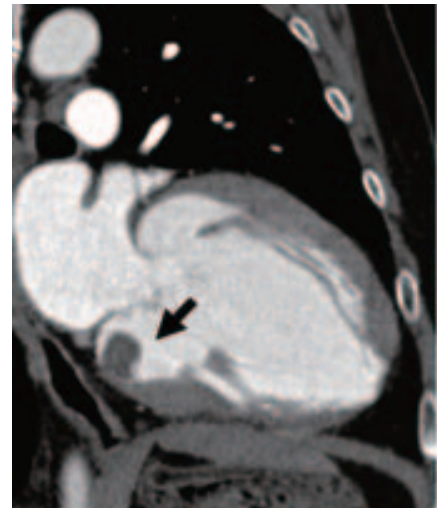

A

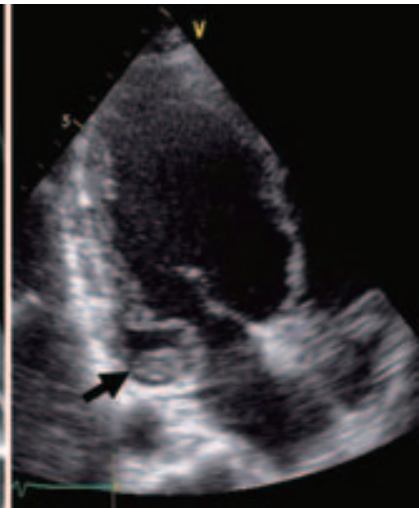

B
Figure 2. Multislice computed tomography (A) and echocardiography (B) showed an aneurysm in the basal posterior septum and posterobasal region of the left ventricle which was associated with a thrombus (arrows).

Echocardiography performed immediately after the thrombectomy showed an aneurysm in the basal posterior septum and posterobasal region, associated with a thrombus (Fig. 2). He underwent an urgent LV thrombectomy at a university hospital. The patient was later diagnosed to have cardiac sarcoidosis. This is a rare case of abdominal aortic saddle embolism due to an LV thrombus which occurred in a patient with cardiac sarcoidosis.

(C) 2007 The Japanese Society of Internal Medicine

http://www.naika.or.jp/imindex.html

${ }^{1}$ Division of Cardiovascular Medicine, Oita Oka Hospital, Oita and ${ }^{2}$ the Second Department of Internal Medicine, Oita University, Oita Received for publication August 21, 2006; Accepted for publication October 30, 2006 Correspondence to Dr Akira Tamura, akira@med.oita-u.ac.jp 